\title{
Saúde laboral - o Adicional de Insalubridade e o direito fundamental ao meio ambiente de trabalho hígido
}

Labor health - the right of laboring in healthy working environment

\section{Leomar Daroncho}

Bacharel em Direito e Engenheiro Civil. Pós-graduado em Direito do Trabalho, Direito Processual e Direito Sanitário. Assistente do Tribunal Superior do Trabalho, em Brasília, Brasil.

Resumo: O efetivo respeito à dignidade humana do trabalhador, titular do direito constitucional fundamental a ver assegurada, no curso de uma relação de trabalho subordinado, a integridade da saúde e a própria vida, está vinculado à observância do parâmetro que pode ser condensado no direito a laborar em um meio ambiente do trabalho hígido. Assim, mostra-se problemático o entendimento que, apesar das várias referências constitucionais que definem os direitos fundamentais, individuais e coletivos, dos trabalhadores, continua a admitir o labor habitual em condições agressivas, mediante remuneração.

Palavras-chaves: saúde; trabalho; insalubridade.

Abstract: The effective respect of worker's human dignity, holder of constitutional right to have integrity of health and live assured in the course of an employeremployee relationship is linked to the, observance of the right of laboring in healthy working environment. Thus, it is problematic to accept the idea of regular work under agressive conditions is excharge of payment, if references that define constitutional fundamental rights, individual, and coletive rights are considered.

Keywords: health, work, unhealthy working environment.

\section{Introdução}

O modelo brasileiro de Estado democrático de direito elegeu como centro de convergência do ordenamento jurídico a dignidade da pessoa humana, 
estabelecendo diretriz que, juntamente com o valor social do trabalho, delimita e impõe o direito fundamental ao trabalho digno.

Nesse contexto, a definição ampla da saúde dentro do modelo de trabalho constitucionalmente protegido remete àquele que se desenvolve segundo os parâmetros estabelecidos para o trabalho decente pela Constituição de 1988 - compreendendo a redução dos riscos inerentes ao trabalho - no Título dos Direitos e Garantias Fundamentais.

Essa constatação, ao mesmo tempo em que qualifica o trabalho constitucionalmente protegido, impõe a análise da compatibilidade das práticas interpretativas usuais com as premissas constitucionais que definem os parâmetros mínimos da regulação do trabalho: direitos fundamentais do trabalho.

Postas essas considerações, surge a seguinte questão: na nossa ordem constitucional, o pagamento do adicional de insalubridade exonera o empregador da responsabilidade pela manutenção do meio ambiente de trabalho hígido?

O enfrentamento da questão proposta, tematizada a partir da hipótese de que o entendimento jurisprudencial dominante comprometeria a efetividade da Constituição, dá-se numa análise crítica e reflexiva referenciada primordialmente na Teoria da Constituição de Dworkin.

A investigação e a leitura crítica do entendimento jurisprudencial dominante se dão na perspectiva da literatura especializada, do Direito Sanitário, do Direito do Trabalho e do Direito Constitucional, com destaque para os autores que promovem a leitura dos direitos sociais a partir e em sintonia com os direitos fundamentais, como propõe o moderno constitucionalismo.

\section{A constitucionalização dos direitos sociais}

\subsection{0 valor social do trabalho e a dignidade humana do trabalhador}

A Constituição da República Federativa do Brasil de 1988 estabelece, no artigo 6을 que "são direitos sociais a educação, a saúde, o trabalho, a moradia, o lazer, a segurança, a previdência social, a proteção à maternidade e à infância, a assistência aos desamparados, na forma desta Constituição". 
Os direitos sociais constituem prestações positivas proporcionadas pelo Estado "direta ou indiretamente, enunciadas em normas constitucionais que possibilitam melhores condições de vida aos mais fracos" (Silva, 1998, p. 289). Tais direitos estão ligados ao direito de igualdade e tendem a realizar a igualização de situações sociais desiguais.

Trata-se do reconhecimento dos novos direitos fundamentais: direitos econômicos, sociais e culturais, que - a partir da Constituição de Weimar, de 1919 - incorporaram-se às constituições de diferentes nações, expressando a ideia de que a felicidade dos homens não se alcança apenas contra o Estado, mas, sobretudo, pelo Estado.

Conforme observado por Sarlet (2003), a abundância, quantitativa e qualitativa, de direitos sociais no texto constitucional confere posição de destaque à Constituição de 1988, tanto na história constitucional brasileira quanto em relação a outras ordens constitucionais.

Noutro giro, Sarlet (2006) anota que o nosso modelo de Estado democrático de direito elegeu como centro de convergência do ordenamento jurídico a dignidade da pessoa humana (art. 1ํ, III, da Constituição).

Nesse contexto, o trabalho, categorizado como direito humano fundamental, no rol dos direitos sociais, requer que sua exteriorização seja acompanhada da marca da dignidade. É oportuno o registro de que o trabalho digno deve ser compreendido como sendo aquele que se desenvolve dentro dos parâmetros estabelecidos para o trabalho decente (Brito Filho, 2004).

Pontue-se que poucas relações são tão propícias à manifestação da desigualdade, inclusive com prejuízos - imediatos ou diferidos - à saúde do trabalhador, como àquelas entabuladas no curso de uma relação de trabalho subordinado.

Desse modo, contextualizando no ambiente e nas relações de trabalho, a dignidade da pessoa humana - protegendo a pessoa do trabalhador contra todo e qualquer ato de cunho degradante e desumano, e ao mesmo tempo garantindo-lhe as condições existenciais mínimas para uma vida saudável - é uma diretriz constitucional que, juntamente com o valor social do trabalho, também fundamento da República Federativa do Brasil, delimita e impõe o direito 
fundamental ao trabalho digno o que, por óbvio, também engloba as condições para a preservação de sua incolumidade física e psíquica.

\subsection{A saúde e o meio ambiente de trabalho}

Ao traçar as linhas básicas do Sistema Único de Saúde - SUS, a Constituição integra o meio ambiente do trabalho ao amplo conceito de meio ambiente a ser protegido (art. 200, VIII).

Destarte, são temas constitucionais tanto a manutenção da saúde do trabalhador quanto a necessidade de que sejam asseguradas as condições de higidez do meio ambiente de trabalho - mediante políticas sociais e econômicas que visem à redução do risco de doença e de outros agravos, como medidas compreendidas na promoção e na proteção da saúde - (artigos 6o e 196).

Dessas disposições deduz-se o conceito de meio ambiente de trabalho como sendo o local em que são desempenhadas atividades laborais, remuneradas ou não, "cujo equilíbrio está baseado na salubridade do meio ambiente e na ausência de agentes que comprometam a incolumidade físicopsíquica dos trabalhadores" (Fiorillo, 2000, p. 21).

Assim, tal como ocorre com os demais ramos do Direito, as questões primordiais do Direito à Saúde e do Direito do Trabalho, na atualidade, já não encontram solução dentro dos limites estreitos das próprias disciplinas, extravasando, necessariamente, para o terreno constitucional (Menezes, 2003).

Necessário considerar, ainda, que a saúde, ou mais precisamente o comprometimento da saúde do trabalhador em decorrência das condições de trabalho, é tema de grande relevância, tanto do ponto de vista da saúde pública, na dimensão coletiva, quanto das possibilidades de inclusão do indivíduo no nosso modelo de sociedade, que valoriza de modo especialmente marcante a produção e a capacidade produtiva.

Sintetizando, é possível afirmar que a saúde do trabalhador, como espécie do direito à saúde constitucionalmente protegido, apresenta-se como direito fundamental inviolável e fora do comércio. 


\subsection{0 direito fundamental ao meio ambiente de trabalho hígido}

A preocupação com os possíveis agravos à saúde, em decorrência do trabalho, remonta ao início do século XVIII, quando Bernardino Ramazzini relacionou os riscos à saúde ocasionados por produtos químicos, poeira, metais e outros agentes (Ramazzini, 2000).

A noção de insalubridade teve origem na medicina urbana - França, final do século XVIII -, tendo como foco a organização do ambiente das cidades e suas relações com as doenças. Surge, então, a medicina da força de trabalho, que sem excluir as demais e tendo incorporado o assistencialismo, desenvolveuse paralelamente ao modo de produção capitalista, inicialmente na Inglaterra (Foucault, 1979).

Investigando a origem da doença e as alterações do equilíbrio homemambiente, Dallari (1988) registra a compreensão de que alterações na saúde podem ser induzidas pelas transformações produtivas, territoriais, demográficas e culturais, incontroláveis nas suas consequências, sem perder de vista o sofrimento individual e o desvio da normalidade biológica ou social.

O contrato de trabalho, por sua vez, é uma relação jurídica complexa que encerra deveres anexos de conduta do empregador, dentre os quais se destaca o dever de proteção (Dallegrave Neto, 2007).

Assim, do ponto de vista da dignidade humana do trabalhador as múltiplas referências constitucionais à saúde ocupacional podem ser sintetizadas no direito a laborar em um meio ambiente do trabalho hígido.

Essa conclusão pode ser deduzida da disposição constitucional que assegurou aos trabalhadores a redução dos riscos inerentes ao trabalho, por meio de normas de saúde, higiene e segurança (art. $7^{\circ}$, caput e inciso XXII), no capítulo dos direitos fundamentais.

Interessante registrar que a inclusão do direito à saúde do trabalhador no complexo maior formado pelo Direito Sanitário, ao menos no que diz respeito aos destinatários da rede de proteção pública, recupera a origem do sistema de saúde no Brasil que, antes do movimento da reforma sanitária, da década de 1980, limitava-se aos trabalhadores regulares. Registrando a restrição dos beneficiários naquele período, a observação de Delduque (2008, p. 105): "Não 
faz muito tempo, a saúde era garantida somente àqueles com carteira de trabalho assinada e mediante contribuição ou àqueles que pudessem pagar por ela".

\section{Adicional de Insalubridade}

\subsection{Histórico}

A compensação pelo trabalho em condições insalubres surge com 0 objetivo de melhorar a alimentação do trabalhador, no contexto da Revolução Industrial, no século XVIII.

Com o tempo tanto a Inglaterra (1760) quanto os Estados Unidos (1830) aboliram o pagamento do adicional (Silva, 1998). Constatou-se que a melhoria na alimentação não evitava as doenças ocupacionais e os trabalhadores procuravam as atividades insalubres buscando os ganhos salariais.

No Brasil, o adicional de insalubridade foi criado pela Lei $n^{0} 185$, de 1936, que instituiu as Comissões de Salário ${ }^{1}$. Dispositivo da Lei permitia que o salário mínimo dos trabalhadores ocupados em serviços insalubres fosse aumentado até a metade.

Editada em 1943, a Consolidação das Leis do Trabalho - CLT, dedica ao adicional de insalubridade a Seção XIII do Capítulo V - Da segurança e da Medicina do trabalho. Define como atividades insalubres aquelas que exponham os empregados a agentes nocivos à saúde acima dos limites de tolerância: em razão da natureza e da intensidade do agente e do tempo de exposição aos seus efeitos (art. 189).

Também atribui ao Ministério do Trabalho a responsabilidade pela aprovação do quadro de atividades consideradas insalubres e de normatizar os critérios para a caracterização da insalubridade (art. 190), e estabelece as situações em que deve ser considerada eliminada ou neutralizada a insalubridade, com medidas ambientais e de utilização de equipamentos individuais de proteção (art. 191).

\footnotetext{
${ }^{1}$ O Decreto-Lei no 399, de 30 de abril de 1938, atribuiu ao Ministério do Trabalho, Indústria e Comércio a organização do quadro das indústrias insalubres que, pela natureza ou método de trabalho, fossem suscetíveis a determinar intoxicações, doenças ou infecções.
} 
Interessante observar a sutileza de que, ajustando-se à compreensão patrimonial do fenômeno, a CLT primeiro define as situações em que seria caracterizada a insalubridade (arts. 189 e 190) e justificariam, portanto, o recebimento do valor correspondente ao adicional. Somente depois (art. 191) ocupa-se da eliminação ou neutralização, e ainda assim com o enfoque econômico.

É possível observar que na Constituição de 1988, meio século depois, ocorre evidente inversão na compreensão e regulação do fenômeno

"Art. 7ํㅗ̃o direitos dos trabalhadores urbanos e rurais, além de outros que visem à melhoria de sua condição social:

$(\ldots)$

XXII - redução dos riscos inerentes ao trabalho, por meio de normas de saúde, higiene e segurança;

XXIII - adicional de remuneração para as atividades penosas, insalubres ou perigosas, na forma da lei;"

E a mudança não é apenas topográfica. O adicional de remuneração para atividades insalubres vem após as disposições gerais do Preâmbulo, dos Princípios Fundamentais, e dos Direitos e Garantias Fundamentais que enunciam e priorizam fundamentos, direitos e garantias - inclusive a dignidade da pessoa humana, o valor social do trabalho e a saúde.

Nesse interregno foi aprovada, em 1983, a Convenção nำ 155 da Organização Internacional do Trabalho - OIT tratando da Saúde e Segurança dos Trabalhadores - normativa internacional ratificada pelo Brasil em 1992 e que é praticamente ignorada dentre nós no que diz respeito à prevenção de doenças ocupacionais.

No art. 3ํ, 'e', a Convenção define o que deve ser entendido por saúde no trabalho:

"e) o termo saúde, em relação com o trabalho, abrange não somente a ausência de afecções ou de doença, mas também os elementos físicos e mentais que afetam a saúde e estão diretamente relacionados com a segurança e higiene no trabalho".

Ajustando-se à realidade e reconhecendo que pode haver dificuldades intransponíveis no que diz respeito às ações preventivas dos empregadores, a Convenção 155 restringe as exigências ao que for razoável e factível (artigo 16). 
Assim, embora tenha origem na transição do modo de produção Revolução Industrial -, é longa a história do adicional de insalubridade, que se mantém, no Brasil, em leis e Normas de um período que antecede à Constituição de 1988.

\subsection{0 entendimento tradicional}

O direito ao adicional de remuneração para atividades insalubres está posicionado em dispositivo posterior àquele que confere 0 direito dos trabalhadores a verem melhorada sua condição social por meio de normas que reduzam os riscos inerentes ao trabalho, ambos no art. $7^{\circ}$ da Constituição.

$\mathrm{Na}$ prática, todavia, transforma-se o encargo do empregador em espécie de obrigação alternativa, podendo optar, conforme the seja mais conveniente (em geral o que for mais barato!), por manter o meio ambiente de trabalho hígido ou pagar o adicional de insalubridade.

Sob outro enfoque, promove-se a leitura invertida das disposições do art. $7^{\circ}$ da Constituição. Contanto que pague 0 adicional (inciso XXIII), 0 empregador poderia exigir o trabalho em condições insalubres, pois o empregado "se obrigou a todo e qualquer serviço compatível com a sua condição pessoal" (art. 456, Parágrafo único, da CLT).

Nessa situação, restaria ao judiciário discutir os limites da agressão para que seja devido o adicional e a base de cálculo da parcela.

Essa é aposição que vem prevalecendo.

No início de 2012 a página eletrônica do Tribunal Superior do Trabalho $^{2}$ mantinha 28 enunciados de jurisprudência que conferem efeitos meramente patrimoniais ao habitual labor em ambiente insalubre. Alguns desses verbetes, inclusive, têm origem em entendimentos construídos ${ }^{3}$ a partir da

\footnotetext{
${ }^{2}$ Disponível em: <http://www.tst.jus.br/jurisprudencia/Index_Enunciados.html>. [data da consulta: 12 fev. 2012].

${ }^{3}$ A redação original da Súmula $n^{\circ} 139$, que admite a integração do adicional de insalubridade à remuneração, é de 1982, fazendo referência ao pagamento em caráter permanente. Logo, admite a exposição permanente ao meio ambiente do trabalho agressivo.
} 
Consolidação das Leis do Trabalho - $\mathrm{CLT}^{4}$, firmados anteriormente à Constituição de 1988.

Trata-se de uma prática que reflete o entendimento mercantilista acerca do direito fundamental do trabalhador à saúde.

\section{Doenças ocupacionais: uma questão de saúde pública}

\subsection{O ambiente agressivo gera agravos à saúde.}

$\mathrm{Na}$ atualidade, pouco contribui para a construção de uma sociedade fraterna, fundada na harmonia social ${ }^{5}$, que tem por fundamento a dignidade da pessoa humana 6 , encarar como "reveses da fortuna" 7 as doenças e os "acidentes súbitos e fortuitos inseparáveis do trabalho industrial" 8.

No ensaio com o sugestivo título "De que Adoecem e Morrem os Trabalhadores", em que analisa as condições de trabalho no campo, Pina Ribeiro (1984) descreve o processo de tomada de consciência da realidade.

Considerando que a doença ocorre num dado ambiente, Rouquayrol (1983) enfatiza a moderna concepção que incorpora a multicausalidade no desencadeamento das doenças. Nessa linha, o estado final provocador de uma doença seria o resultado da sinergia de múltiplos fatores: políticos, econômicos, sociais, culturais, psicológicos, genéticos, biológicos, físicos e químicos.

Assim, anda que se revele complexa a tarefa de identificar por inteiro as causas dos acidentes de trabalho, seria mesmo surpreendente que, num contexto em que se assumiu o caráter contraprestacional do labor habitual em condições agressivas ao trabalhador, não fossem produzidos os resultados que,

\footnotetext{
${ }^{4}$ O Decreto-Lei no 5.452 do Presidente Getúlio Vargas que aprovou a Consolidação das Leis do Trabalho, é de 1\%/5/1943.

${ }^{5}$ Preâmbulo da Constituição de 1988.

${ }^{6}$ Art. 1ํ, III, da Constituição de 1988.

${ }^{7}$ Carta Encíclica "Rerum Novarum" do Papa Leão XIII, sobre as condições dos operários. Disponível em: <http://www.vatican.va/holy_father/leo_xiii/encyclicals/documents/hf_I-xiii_enc_15051891_rerumnovarum_po.html>. [data da consulta: 14 fev. 2012].

${ }^{8}$ Papa Leão XIII, op. cit. A evolução da abordagem da Igreja Católica, na perspectiva preventiva, e especificamente a inclusão do ambiente de trabalho dentre os determinantes sociais da saúde, será retomada em capítulos seguintes tendo em vista a Campanha da Fraternidade da CNBB/2012, que tem por tema o oportuno tema: Fraternidade e Saúde Pública.
} 
lógica e inevitavelmente, decorrem da contumaz exposição do trabalhador a agentes nocivos à saúde, acima dos limites de tolerância.

A missão é ainda mais simplificada quando se observa que a lei previdenciária - Lei no 8.213/91 - reconhece a concausalidade 9 .

Pontue-se que para os propósitos desse estudo o estabelecimento da causalidade e a efetiva reparação, da vítima e da previdência, assumem importante função pedagógica, militando em favor dos comportamentos preventivos.

Logo, diante da constatação de enfermidades ligadas ao trabalho e havendo notícias do trabalho em ambiente insalubre, ainda que remotamente no tempo, mostra-se factível a definição da relação de causalidade e a consequente reparação, da vítima e da previdência.

\subsection{Informações oficiais sobre doenças ocupacionais e seus custos}

Considerando a banalização do entendimento que autoriza o habitual agravo à saúde do trabalhador, mediante contraprestação financeira, não surpreende que os dados da infortunística laboral ${ }^{10}$ no período compreendido entre 2005 e 2009, sejam de proporções alarmantes.

Dados oficiais publicados na página eletrônica do $\mathrm{TST}^{11}$ informam que entre 2005 e 2009 o número anual de acidentes de trabalho registrados saltou de 499.680 para 723.452 .

Comparado as estatísticas de acidentes do trabalho no Brasil com números de uma guerra civil, Oliveira (op. cit. p. 33) informa "que diariamente cerca de 48 pessoas deixam definitivamente o mundo do trabalho no Brasil".

Logicamente, os custos para a sociedade brasileira também são de uma grandeza estarrecedora, como estampa a nota que segue:

\footnotetext{
9 "Art. 21. Equiparam-se também ao acidente do trabalho, para os efeitos desta Lei: I - acidente ligado ao trabalho que, embora não tenha sido a causa única, haja contribuído diretamente para a morte do segurado, para a redução ou perda da sua capacidade para o trabalho, ou produzido lesão que exija atenção médica para a sua recuperação."

${ }^{10}$ Há indicativos de que os dados oficiais sobre doenças ocupacionais no Brasil padecem do vício da subnotificação.

${ }^{11}$ Disponível em: <http://www.tst.jus.br/prevencao/estatistica.html>. [data da consulta: 31 jan. 2012].
} 
"Dados estatísticos do INSS apontam que no Brasil, em 2009, ocorreu cerca de uma morte a cada 3,5 horas, motivada pelo risco decorrente dos fatores ambientais do trabalho e ainda cerca de 83 acidentes e doenças do trabalho reconhecidos a cada uma hora na jornada diária. No mesmo ano, cerca de 43 trabalhadores por dia não retornaram ao trabalho devido à invalidez ou morte. Os benefícios pagos pelo governo, em 2009, a esse título, somam $\mathrm{R} \$ 14,20$ bilhões $^{12}$." $^{\circ}$

Assim, a questão também apresenta grande relevância sob o ponto de vista das finanças públicas. No mesmo período a proposta orçamentária global do Executivo para o Ministério da Saúde ${ }^{13}$ foi de $R \$ 59,4$ bilhões.

Ao lado do drama social e humano que permeia a questão, os dados oficiais permitem concluir que a infortunística do trabalho consome cerca de $25 \%$ do montante de recursos destinados ao Ministério da Saúde.

A questão também transborda para importantes consequências previdenciárias. O trabalho habitual em meio ambiente agressivo enseja a aposentadoria especial, com tempo de contribuição reduzido, a teor do art. 57 da Lei no 8.213/1991,

Observando os dados, Ibrahim (2012, p. 621) convoca à postura dirigida a ações voltadas à saúde ocupacional, eliminando as atividades nocivas que seriam, "no máximo, admitidas em raríssimas hipóteses". Também registra a formação do consenso no sentido de que a "jubilação antecipada" seria uma forma de legitimação da "violência frente à saúde do trabalhador, o que não condiz com um ordenamento jurídico centrado na dignidade da pessoa humana".

Logo, a adoção de uma severa postura preventiva, alterando a prática reparatória e patrimonialista dos direitos fundamentais, poderia produzir importantes resultados sobre a substancial quantia de recursos despendida com a infortunística do trabalho.

\footnotetext{
${ }^{12}$ Disponível em: < http://www.tst.jus.br/prevencao/noticia1.html>. [data da consulta: 31 mai. 2011].

${ }^{13}$ Disponível em: < http://contasabertas.uol.com.br/ WebSite/noticias /detalhenoticias. aspx?id=2815>. [data da consulta: 31 mai. 2011].
} 


\section{A insalubridade no Direito Comparado}

\subsection{MERCOSUL}

O Tratado de Assunção para a Constituição de um Mercado Comum ${ }^{14}$, firmado em dia 26 de março de 1991, entre a Argentina, o Brasil, o Paraguai e o Uruguai em Assunção, tem como um dos objetivos fundamentais da integração a busca pelo desenvolvimento econômico com justiça social.

Faz-se necessário o registro de que dentre os nossos vizinhos do MERCOSUL a única Constituição a referir o trabalho em condições insalubres é a da República do Paraguai ${ }^{15}$.

Ainda assim, a Constituição paraguaia determina que a lei preveja jornada mais favorável para os que laboram em ambientes insalubres ou perigosos (artigo 91).

A Constituição Uruguaia ${ }^{16}$ determina a proteção ao ambiente de trabalho sem mencionar qualquer sanção ou pagamento de adicional em caso de descumprimento.

A Constituição da Argentina não cuida diretamente da matéria. Todavia, a sua constituição contém interessante dispositivo ${ }^{17}$ (art. 31) que confere aos tratados internacionais, celebrados com as potências estrangeiras, o status de lei suprema da nação. Dito de outro modo, tais tratados estão no nível da supremacia constitucional.

Ainda na Argentina, a legislação infraconstitucional, a Lei $n^{\circ} 20.744$, de 1976 - Regimen de Contrato de Trabajo $^{18}$ - contém disposição que encaminha o

\footnotetext{
${ }^{14}$ Disponível em: <http://www2.mre.gov.br/unir/webunir/bila/esp/artigos/3artigo.htm>. [data da consulta: 2 mar. 2012].

15 "Artículo 91. DE LAS JORNADAS DE TRABAJO Y DE DESCANSO - La duración máxima de la jornada ordinaria de trabajo no excederá de ocho horas diarias y cuarenta y ocho horas semanales, diurnas, salvo las legalmente establecidas por motivos especiales. La ley fijará jornadas más favorables para las tareas insalubres, peligrosas, penosas, nocturnas o las que se desarrollen en turnos continuos rotativos". Disponível em: http://www.constitution.org/cons/paraguay.htm>. [data da consulta: 20 mar. 2012].

${ }^{16}$ Disponível em: <http://www0.parlamento.gub.uy/constituciones/const004.htm>. [data da consulta: 3 mar. 2012].

17 Disponível em: <http://www.senado.gov.ar/web/interes/constitucion/capitulo1.php>. [data da consulta: 3 mar. 2012].

18 Ao menos no plano normativo, os trabalhadores argentinos estão protegidos, no nível constitucional, por convenções como a de oㅜ 155 da OIT - que dispõe sobre a segurança e a saúde dos trabalhadores - obrigando-se a prevenir os acidentes e os danos à saúde que sejam consequência do trabalho, reduzindo ao mínimo, na medida em que isso seja razoável e factível, as causas dos
} 
problema do trabalho em ambientes insalubres para solução substancialmente distinta da nossa.

De início, a fiscalização orienta o empregador a adequar o ambiente às condições de salubridade. Caso não sejam observadas as determinações, a autoridade qualifica as atividades como insalubres, fato que implica a redução da jornada de trabalho (6 horas), sem redução dos salários (art. 200).

São semelhantes as disposições do novo Código do Trabalho do Paraguai - Lei no 213, de 1993 (Código del Trabajo) - quanto às consequências do trabalho em condições classificadas como insalubres pelas autoridades, importando na redução da jornada para 6 horas, sem redução de salários (artigo 198).

Da mesma forma, na legislação infraconstitucional uruguaia - Lei no 11.577 - há dispositivo prevendo a redução da jornada de trabalho, sem redução dos salários, para os que laboram em ambientes agressivos á saúde (artigos 1ํe $\left.7^{\circ}\right)$.

Assim, no aspecto normativo, é bastante superior a solução encontrada pelos nossos vizinhos do MERCOSUL ao inquietante problema do trabalho em condições insalubres, uma vez que impõem a redução do tempo de exposição ao agente insalutífero.

\subsection{Espanha}

A referência à legislação espanhola justifica-se tanto pela proximidade das experiências jurídicas e culturais quanto pela participação na Rede lberoamericana de Direito Sanitário, que compreende uma estratégia de articulação e cooperação entre pessoas e instituições do âmbito do Direito Sanitário nos países membros da comunidade iberoamericana ${ }^{19}$.

O Real Decreto espanhol nำ1561, de 1995, que dispõe sobre jornadas especiais de trabalho, contém uma seção dedicada especificamente ao tema:

\footnotetext{
riscos inerentes ao meio ambiente de trabalho - artigo 4.2. Disponível em: <http://infoleg.mecon.gov.ar/infoleglnternet/anexos/25000-29999/25552/texact.htm>. [data da consulta: 25 fev. 2012].

${ }^{19}$ Disponível em: <http://www.fiocruz.br/fiocruzbrasilia>. [data da consulta: 2 mar. 2012].
} 


\begin{abstract}
"SECCIÓN I. TRABAJOS EXPUESTOS A RIESGOS AMBIENTALES

Artículo 23. Limitación de los tiempos de exposición al riesgo.

Procederá la limitación o reducción de los tiempos de exposición a riesgos ambientales especialmente nocivos en aquellos casos en que, pese a la observancia de la normativa legal aplicable, la realización de la jornada ordinaria de trabajo entrañe un riesgo especial para la salud de los trabajadores debido a la existencia de circunstancias excepcionales de penosidad, peligrosidad, insalubridad o toxicidad, sin que resulte posible la eliminación o reducción del riesgo mediante la adopción de otras medidas de protección o prevención adecuadas".
\end{abstract}

A exposição ao ambiente insalubre requer, além da redução da jornada, que se demonstre a impossibilidade de eliminação ou redução dos riscos ambientais por outras medidas de proteção ou prevenção adequadas.

Eis uma sutileza que torna a disposição ainda mais ajustada aos propósitos que vem sendo defendidos nesse estudo - prevenção e precaução - do que as regulamentações sul-americanas analisadas.

A referência às experiências do Direito Comparado pode ser muito importante tendo em vista o recente entendimento do Supremo Tribunal Federal quanto à inconstitucionalidade do art. 192 da Consolidação das Leis do Trabalho ${ }^{20}$ (tecnicamente, não recepção pela Constituição de 1988), externado na discussão que deu origem à Súmula Vinculante $\mathrm{n} \times 4$.

Por mais paradoxal que possa parecer, nas manifestações dos Ministros da Suprema Corte restou consignado que até que novo critério seja adotado, por lei ou por negociação ou sentença coletiva, continuará a ser aplicado o dispositivo tido por inconstitucional ${ }^{21}$. Logo, no meio jurídico, aguarda-se uma nova lei sobre o tema. $\mathrm{E}$, de lege ferenda, essas balizas do Direito Comparado podem representar contribuição valiosa à preservação da saúde dos trabalhadores.

\footnotetext{
${ }^{20}$ Ao mesmo tempo em que reconheceu a inconstitucionalidade da utilização do salário mínimo como base de cálculo do adicional de insalubridade a Súmula Vinculante o 4 do Supremo Tribunal Federal vedou a substituição desse parâmetro por meio de decisão judicial. A polêmica judicial acerca do tema, que favorece a proposta de revisão por completo de antigas práticas, será retomada nos próximos capítulos.

${ }^{21} \mathrm{O}$ mesmo entendimento vem sendo adotado pelo Tribunal Superior do Trabalho, sob o fundamento de que a Suprema Corte teria adotado a técnica decisória conhecida no direito constitucional alemão como declaração de inconstitucionalidade sem pronúncia da nulidade, ou seja, a norma, não obstante ser declarada inconstitucional, continua a reger as relações obrigacionais, em face da impossibilidade de o Poder Judiciário se substituir ao legislador para definir critério diverso para a regulação da matéria.
} 


\section{A supremacia dos direitos sociais constitucionais}

Discorrendo sobre o fenômeno da constitucionalização dos direitos sociais Canotilho (2003) assinala tanto o aspecto da incorporação, com o reconhecimento formal das normas no texto constitucional, quanto da consequente subtração de sua temática do ambiente de livre disponibilidade do legislador ordinário. Por óbvio, também não há essa disponibilidade nas relações horizontais, entre particulares.

A abordagem do novo constitucionalismo (ou neoconstitucionalismo) apresenta infindáveis possibilidades de investigação acadêmica ${ }^{22}$, notadamente quando se relembra que o contrato de trabalho é uma relação jurídica complexa, dinâmica e solidária que, além das obrigações principais, encerra deveres anexos de conduta do empregador, dentre os quais se destaca o dever de proteção (Dallegrave Neto, 2007) -, cujo aprofundamento escapa aos propósitos desse estudo.

O movimento enaltece a força normativa da Constituição que, assim, deixa de ser um mero catálogo destinado a regular a distribuição de competências e a dispor sobre recomendações políticas e morais. Ao contrário, assume a posição central no ordenamento, com preceitos vinculantes, capazes de conformar a realidade.

Mendes (2008) registra que o neoconstitucionalismo confere relevo à primazia do princípio da dignidade da pessoa humana, que deve ser protegida e promovida pelos Poderes Públicos e pela sociedade.

Gestada nesse contexto, a Constituição de 1988 incorporou com destaque os direitos sociais no âmbito dos direitos e garantias fundamentais (art. $6^{\circ}$ ). Também destinou um título específico à ordem social, a partir do artigo 193.

Essas premissas são fundamentais, pois, conforme já afirmado, são temas constitucionais tanto a manutenção da saúde do trabalhador quanto a necessidade de que sejam efetivamente asseguradas as condições de higidez do meio ambiente de trabalho, como medidas compreendidas na promoção e na proteção da saúde.

\footnotetext{
${ }^{22}$ No Brasil, o tema é tratado de forma bastante adequada por Sarmento (2006).
} 
Impõe-se, portanto, uma análise crítica e reflexiva acerca do entendimento sedimentado, a partir da contribuição efetiva da Teoria da Constituição, na perspectiva dworkiana ${ }^{23}$ do direito como integridade.

Uma postura construtivista nessa análise exige a reflexividade ética com os princípios hermenêuticos de modo a impedir que, contrariamente aos direitos fundamentais, as tradições "se legitimem de maneira autônoma e acrítica" (Carvalho Netto, 2011, p. 76), ignorando a reformulação processada pelo constituinte de 1988.

Em suma, mostra-se necessário refletir criticamente contribuindo para a construção de entendimentos que viabilizem a perspectiva emancipatória ${ }^{24}$ dos direitos fundamentais previstos na Constituição.

A discussão acerca da manutenção do entendimento jurisprudencial que ignora a vigência de uma nova ordem constitucional é extremamente relevante em nosso sistema, uma vez que, além da parte visível - fase inicial de formulação -, a norma jurídica passa por etapas seguintes, menos visíveis, quando, na reconstrução, entra em choque com o meio e está menos exposta à crítica (Viana, 1999).

Assim, é inescapável a conclusão de que a interpretação da Constituição à luz da legislação infraconstitucional, anterior e contrária a ela, e a atribuição de efeitos meramente patrimoniais ao habitual desrespeito a um direito fundamental comprometem a formulação de Dworkin (1999) de que a Constituição constitui uma comunidade fundada sobre princípios comuns.

O entendimento acerca do adicional de insalubridade sinaliza a prevalência de práticas constitucionais típicas da ordem anterior. A adoção continuada e acrítica do entendimento termina por atingir supremacia de que se deve revestir a Constituição. O desgaste da força normativa da Constituição

\footnotetext{
${ }^{23}$ Segundo Dworkin (1999, p. 264), "A integridade exige que as normas públicas da comunidade sejam criadas e vistas, na medida do possível, de modo a expressar um sistema único e coerente de justiça e equidade na correta proporção. Uma instituição que aceite esse ideal às vezes irá, por esta razão, afastar-se da estreita linha das decisões anteriores, em busca de fidelidade aos princípios concebidos como mais fundamentais a esse sistema como um todo".

24 Expressão de Flávia Piovesan para a função dos Direitos Humanos. Disponível em: <http://www.tst.gov.br/Ssedoc/PaginadaBiblioteca/revistadotst/Rev_75/Rev_75_1/piovesanflavia.pdf>. [data da consulta 6 out. 2011].
} 
acarreta a perda "da mística de sua intangibilidade" (Carvalho Netto, 2011, p. 884).

Retomando a discussão específica acerca da compatibilidade do adicional de insalubridade com as disposições constitucionais que asseguram os direitos fundamentais do trabalhador, pode-se afirmar que a patrimonialização dos direitos fundamentais retira-lhes o papel de "barreira de fogo" (Carvalho Netto, 2011, p. 15) inegociável, comprometendo a efetividade do direito social fundamental ao meio ambiente de trabalho hígido.

O entendimento também afronta os compromissos da República Federativa do Brasil, no plano internacional, uma vez que a monetização indiscriminada dos agravos à saúde do trabalhador é de difícil harmonização com a diretiva da Organização Internacional do Trabalho ${ }^{25}$ de que o trabalho não é uma mercadoria.

Nesta senda, é apenas aparente a contradição existente entre o conjunto das normas do texto constitucional que protegem a saúde do trabalhador e o meio ambiente do trabalho com a disposição que confere o direito ao adicional de remuneração para as atividades insalubres (art. $7^{\circ}$, XXIII).

Essa também é a conclusão de Dallegrave Neto (2007, p. 202):

"Com esteio nesse dispositivo (art. 7ํXII, da Constituição), o trabalhador tem o direito fundamental de trabalhar em ambiente hígido e salubre com redução e prevenção dos riscos concernentes à atividade laborativa de modo a preservar a sua saúde e segurança física. Tal regramento tem como destinatário o empregador; contudo, vincula o legislador e o julgador".

Assinale-se ser indispensável considerar que as relações de trabalho são essencialmente relações sociais de desigualdade e que o "trabalho pode tornar-se um verdadeiro laboratório de experimentação e aprendizado da injustiça e da iniquidade" (Dejours, 2006, p. 140), para os seus beneficiários e/ou vítimas.

A previsão constitucional do adicional, nas raras hipóteses em que pode ser admitido o trabalho em condições insalubres, foi estabelecida a favor do trabalhador e não contra ele (art. $7^{\circ}$, caput/CF). Assim, não elimina a norma geral de garantia do ambiente de trabalho saudável, com redução dos riscos inerentes ao

${ }^{25}$ Constituição da Organização Internacional do Trabalho - Declaração de Filadélfia, 1944 (Sussekind, 2007). 
exercício do labor, e que deverá ser sempre buscado, até o limite científico e tecnológico, tendo por fundamento maior o princípio da dignidade do ser humano.

\section{A janela de oportunidade}

O combate à reiterada prática jurisprudencial demanda que a discussão seja ambientada em espaço menos refratário à reflexão. Ocorre que há um conjunto de iniciativas que sinalizam importante janela de oportunidade para a revisão do entendimento "sedimentado segundo a ótica antiga" (Viana, 1999, p. 893).

Num primeiro plano, a candente discussão jurídica acerca da base de cálculo do adicional de insalubridade.

Noutro flanco, o lançamento da campanha do Tribunal Superior do Trabalho - TST em favor da prevenção dos acidentes de trabalho.

Também se insere nesse contexto a 14를 Conferência Nacional de Saúde CNS de 2011, que teve uma diretriz - nº 14, Integrar e ampliar políticas e estratégias para assegurar atenção e vigilância à saúde ao trabalhador - aprovada sem ressalvas $^{26}$.

No plano internacional, merece destaque a criação da Rede Iberoamericana de Direito Sanitário. Nos dias 31 de agosto e $1^{\circ}$ de setembro de 2011 foi realizado na Universidade de Buenos Aires (UBA) o I Congresso Ibero-americano de Direito Sanitário, com a participação de representantes de vários países: Brasil, Argentina, Costa Rica, Uruguai, Chile, Colômbia e Espanha; tendo por lema uma assertiva que se ajusta à premissa que orienta esse estudo, particularmente em relação ao ser humano trabalhador: "El derecho de la salud como un derecho humano fundamental en la agenda de Iberoamerica".

Outro importante ator social que se agrega à discussão é a Conferência Nacional dos Bispos do Brasil. A Campanha da Fraternidade de 2012, com o tema: "A Fraternidade e Saúde Pública"; traz um texto base ${ }^{27}$ para a reflexão eclesial focando a questão do trabalho indicando relações portadoras "de sinais de morte, para suscitar ações transformadoras".

${ }^{26}$ Disponível em: <http://conselho.saude.gov.br/web_14cns/index.html>. [data da consulta: 31 mar. 2012].

${ }^{27}$ Disponível em: <http://www.cnbb.org.br/site/campanhas/fraternidade> [data da consulta: 25 fev. 2012]. 
Portanto, revela-se certo sincronismo que pode favorecer a mudança das velhas práticas, nessa área particularmente sensível das relações humanas: o mundo do trabalho.

\section{Considerações finais}

O princípio constitucional da dignidade da pessoa humana, contextualizado no ambiente e nas relações de trabalho, constitui diretriz que, juntamente com o valor social do trabalho, delimita e impõe o direito fundamental ao trabalho digno.

A saúde do trabalhador, compreendida no amplo direito à saúde, apresenta-se como direito fundamental inviolável e fora do comércio. Assim, a sua preservação impõe-se tanto ao empregador quanto ao Estado. Destarte, é de se esperar que eventuais lesões a esse direito fundamental encontrem uma resposta satisfatória do aparato jurídico.

A garantia constitucional ao meio ambiente de trabalho hígido, como direito fundamental, desautoriza 0 entendimento que reduz à simples patrimonialização os efeitos de sua transgressão habitual. Do contrário, seria necessário admitir que se continue a interpretar a Constituição à luz da legislação infraconstitucional, anterior e contrária a ela.

Necessário considerar que o caráter supralegal da Constituição, como uma aquisição evolutiva do processo de modernização da sociedade, condiciona a validade de todas as demais leis. A Constituição deve necessariamente ser tomada como a norma jurídica suprema do país.

Presente o sincronismo de variadas iniciativas visando à preservação da saúde do trabalhador, assinalou-se que a simultânea atenção ao tema favorece a mudança das velhas práticas, nessa área particularmente sensível das relações humanas: o mundo do trabalho.

Uma provocadora história da sabedoria sufi descreve o diálogo de um homem com um amigo que procura sob a luz de um poste. Descobre que o amigo procura uma chave que havia perdido.

O homem indaga se o amigo tem certeza de que perdera a chave ali. Descobre que não. A chave fora perdida em outro local, mas lá está escuro demais para a busca. 
Situação semelhante acontece com a atual polêmica acerca da base de cálculo do adicional de insalubridade. A partir dos dispositivos constitucionais que conduzem ao direito fundamental do trabalhador de laborar em um meio ambiente hígido, mostra-se nebulosa a busca (às escuras) pela definição da remuneração do trabalho habitual em condições insalubres.

A luz certamente está noutro local. Estaria mais em ordem com as disposições constitucionais a pura e simples vedação à rotineira exploração do trabalho humano nessas condições.

E já é tempo de conferir concretude ao princípio da dignidade da pessoa humana, que deve deixar de ser mera cláusula retórica com assento constitucional. 


\section{Referências}

BONDER. Nilton. Fronteiras da inteligência. Rio de Janeiro : Campus, 2001, 200 p. ISBN: 85-352-0866-6.

BRITO FILHO, José Claudio Monteiro de. Trabalho decente: análise jurídica da exploração, trabalho forçado e outras formas de trabalho indigno. São Paulo : LTr, 2004, 136 p.. ISBN: 978-85-3611-591-7.

CANOTILHO, José Joaquim Gomes. Direito Constitucional e teoria da Constituição. 7 ed. Coimbra : Almedina, 2003, 1522 p. ISBN: 972-40-21068.

CARVALHO NETTO, Menelick; SCOTTI, Guilherme. Os direitos fundamentais e a (in) certeza do direito: produtividade das tensões principiológicas e a superação do sistema de regras. Belo Horizonte : Fórum, 2011, 167 p. ISBN . 978-85-7700-4140 .

DALLARI, Sueli Gandolfi. O direito à saúde. Revista Saúde Pública. [on line], 22(1): 57-63, fev. 1988. ISSN 0034-8910. [data da consulta: 15 ago. 2011]. Disponível em: <http://www.scielo.br/scielo.php?script=sci_arttext\&pid=S0034$89101988000100008 \&$ Ing $=$ pt\&nrm=isso>.

DALLEGRAVE NETO, José Affonso. Responsabilidade civil no direito do trabalho, 2. ed., São Paulo : LTR, 2007, 374 p. ISBN 9788536109558.

DEJOURS, Christophe. A banalização da injustiça social. 7 ed. Tradução de Luiz Alberto Monjardim. Rio de Janeiro : FGV, 2006, 160 p. ISBN 85-225-0266-8.

DELDUQUE, Maria Célia. Tijolo por tijolo: a construção permanente do direito à saúde. In: COSTA, Alexandre Bernardino et al. (orgs). O Direito achado na rua: Introdução crítica ao direito à saúde. p. 103-110. Introdução. - Brasília: CEAD/UnB, 2009, 460 p. ISBN: 978-85-7804-025-3.

DWORKIN, Ronald. O império do direito. Tradução Jefferson Luiz Camargo. São Paulo : Martins Fontes, 1999, 513 p. ISBN: 8533610122.

FIORILlO, Celso Antonio Pacheco. Curso de Direito Ambiental brasileiro. São Paulo : Saraiva, 2000, 290 p. ISBN 85-02-03084-1.

FOUCAULT, Michel. Microfísica do Poder. Rio de Janeiro : Graal, 1979, 295 p. ISBN8570380194. 
IBRAHIM, Fábio Zambitte. Curso de Direito Previdenciário. 17 ed. Rio de Janeiro : Impetus, 2012. ISBN 9788576265597.

MENDES, Gilmar Ferreira; COELHO, Inocêncio Mártires; BRANCO, Paulo Gustavo Gonet. Curso de Direito Constitucional. 2 Ed. São Paulo: Saraiva, 2008, 1432 p. ISBN: 978-85-02068-99-5

MENEZES, Mauro de Azevedo. Constituição e reforma trabalhista no Brasil: interpretação na perspectiva dos direitos fundamentais. São Paulo : LTr, 2004, 368 p. ISBN 85-36-10429-5.

OLIVEIRA, Sebastião Geraldo. Indenização por acidente de trabalho. São Paulo : LTr, 2008. 549 p. ISBN 978-85-361-1331-9.

PINA RIBEIRO, Herval; CASTRO LACAZ, Francisco Antonio de. De que adoecem e morrem os trabalhadores. São Paulo : DIESAT/IMESP, 1984, 236 p. OCLC 15251446.

RAMAZZINI, B. As doenças dos trabalhadores. São Paulo : Fundacentro, 2000, 235 p. ISBN 978-85-98177-46-1.

ROUQUAYROL, Maria Zélia; ALMEIDA FILHO, Naomar de. Epidemiologia e saúde. 6 ed. Rio de Janeiro : MEDSI, 2003, 728 p. ISBN 85-7199-351-3.

SARLET, Ingo Wolfgang. Direitos fundamentais sociais: estudos de direito constitucional, internacional e comparado. IN: SARLET, Ingo Wolfgang (org). Rio de Janeiro : Renovar, 2003, 508 p. ISBN 978-85-71-47322-5

SARLET, Ingo Wolfgang. Dignidade da Pessoa Humana e Direitos Fundamentais. 4 Ed. Porto Alegre : Livraria do Advogado. 2006, 158 p. ISBN: 8573484012978.

SILVA, José Afonso da. Curso de Direito Constitucional Positivo. São Paulo : Malheiros, 1998, 863 p. ISBN: 85-74-20207-X.

SARMENTO, Daniel. Direitos fundamentais e relações privadas. Rio de Janeiro : Lumen Juris Editora, 2006. 362 p. ISBN ISBN-978-85-375-762-9.

BRASIL. Tribunal Superior do Trabalho: Disponível em: <http://www. tst.jus.br/ prevencao/ noticia2.html> [data do acesso: 11 ago. 2011].

VATICANO: Disponível em: <http://www.vatican.va/holy_father/leo_xiii/encyclicals/ documents/hf_I-xiii_enc_15051891_rerum-novarum_po.html> [data da consulta: 14 fev. 2012]. 
VIANA, Márcio Túlio. A proteção social do trabalhador no mundo globalizado - o direito do trabalho no limiar do Século XXI. Revista LTr São Paulo, 63(7):885-89, jul. 1999. ISSN 554672. 